\title{
Effects of Acute Low-Temperature Events on Development of Erysiphe necator and Susceptibility of Vitis vinifera
}

\author{
Michelle M. Moyer, David M. Gadoury, Lance Cadle-Davidson, Ian B. Dry, \\ Peter A. Magarey, Wayne F. Wilcox, and Robert C. Seem
}

First, second, third, fourth, sixth, and seventh authors: Department of Plant Pathology and Plant-Microbe Biology, Cornell University, New York State Agricultural Experiment Station, Geneva 14456; third author: United States Department of Agriculture-Agricultural Research Service Grape Genetics Research Unit, Geneva, NY 14456; fourth author: CSIRO Plant Industry, Glen Osmond, South Australia 5064, Australia; and fifth author: Magarey Plant Pathology, Loxton, South Australia 5333, Australia. Accepted for publication 1 July 2010.

\begin{abstract}
Moyer, M. M., Gadoury, D. M., Cadle-Davidson, L., Dry, I. B., Magarey, P. A., Wilcox, W. F., and Seem, R. C. 2010. Effects of acute lowtemperature events on development of Erysiphe necator and susceptibility of Vitis vinifera. Phytopathology 100:1240-1249.

Growth and development of Erysiphe necator (syn. Uncinula necator) has been extensively studied under controlled conditions, primarily with a focus on development of grapevine powdery mildew within the optimal temperature range and the lethal effects of high temperatures. However, little is known of the effect of cold temperatures (above freezing but $<8^{\circ} \mathrm{C}$ ) on pathogen development or host resistance. Pretreatment of

when tissues were subsequently inoculated. Furthermore, nascent colonies exposed to similar cold events exhibited hyphal mortality, reduced expansion, and increased latent periods. Historical weather data and an analysis of the radiational cooling of leaf tissues in the field indicated that early-season cold events capable of inducing the foregoing responses occur commonly and frequently across many if not most viticultural regions worldwide. These phenomena may partially explain (i) the unexpectedly slow development of powdery mildew during the first month after budbreak in some regions and (ii) the sudden increase in epidemic development once seasonal temperatures increase above the threshold for acute cold events.
\end{abstract} susceptible Vitis vinifera leaf tissue by exposure to cold temperatures ( 2 to $\leq 8^{\circ} \mathrm{C}$ for 2 to $8 \mathrm{~h}$ ) reduced infection efficiency and colony expansion

Powdery mildews occupy a distinct ecological and biological niche. Among the plant-pathogenic fungi, they are unique in that, with the exception of the haustoria in parasitized epidermal cells, the preponderance of their biomass is external to the host. This uniquely external and exposed condition makes them especially responsive to a variety of environmental factors, including temperature $(4,7,37)$, solar radiation (2), and atmospheric humidity (7). A number of simple weather-driven models designed to predict powdery mildew infection risk and general epidemic development have been developed from reanalysis of data generated in laboratory and greenhouse studies of the disease $(24,29,36)$. However, such models focus on epidemic development when conditions are in the optimal growth range for the pathogen, with particular emphasis on regional weather phenomena that alter epidemic development. There is close agreement among several laboratory and controlled environment studies with respect to the cardinal temperatures defined for spore germination and infection of host tissues by Erysiphe necator $(4,7,37)$. Simple regression models based on germination, infection, or colony expansion data generated at various controlled temperatures are the basis of some of the most widely used advisory systems for timing of fungicide applications $(24,29)$. However, deployment of the advisory system often requires an empirical approach to adjust model outputs to provide a better fit to observed disease development in vineyards. Some of these output adjustments, in particular

Corresponding author: M. M. Moyer; E-mail address: mmm78@cornell.edu

* The $\boldsymbol{e}$-Xtra logo stands for "electronic extra" and indicates that Figure 3 appears in color online.

doi:10.1094/PHYTO-01-10-0012

(c) 2010 The American Phytopathological Society
Additional keywords: induced resistance.

those relating to suboptimal temperatures, cannot be easily reconciled to the effects observed in laboratory studies. For example, Delp (7) demonstrated that germination of conidia on grapevine leaves at $17^{\circ} \mathrm{C}$ was reduced by only $29 \%$, and subsequent infection was reduced by $50 \%$, compared with the optimum of $26^{\circ} \mathrm{C}$. Similar results were reported for ascospore germination and infection (14). However, some advisory systems rate the risk of infection as low at temperatures below 15 to $19^{\circ} \mathrm{C}$ $(5,24,29)$. Additionally, disease development in the field has been investigated using ambient air temperature, which can differ substantially from leaf surface temperatures in field environments. Leaf surface temperature in direct sun can exceed ambient air temperature by several degrees (2) and, at night, ambient air temperature can exceed leaf surface temperature by several degrees due to radiational cooling of leaf tissues (40).

These disparities between (i) the effects of temperature on disease development in model advisories versus lab studies and on ambient air versus leaf surface temperature, combined with (ii) the unexpectedly slow development of powdery mildew epidemics compared with model forecasts that we have observed locally, led us to initiate a number of biological and epidemiological studies on the effects of acute, cold-temperature events (above freezing but $<8^{\circ} \mathrm{C}$ ) on grape tissue response to powdery mildew infection and powdery mildew development (17,30-32). We consistently obtained responses that were similar to those observed in leaves transitioning to or in an ontogenically resistant state (i.e., quantitatively reduced infection efficiency, increased latent period, and increased mortality of hyphae in the colony) (30). In the present study, we investigate the impact of acute cold events on the induction of a resistance response in susceptible Vitis vinifera leaf tissues and upon the development of nascent mildew colonies under both controlled conditions and in the field. 
We also show that acute cold events are not solely a feature of cold climates but are common features early in the growing season in several warm-climate viticultural regions.

\section{MATERIALS AND METHODS}

Grapevine cultivar selection and susceptibility to powdery mildew. Three cultivars of a highly susceptible grapevine species, $V$. vinifera (14), were used in experiments. Leaves of $V$. vinifera cvs. Chardonnay, Riesling, Pinot noir, and Cabernet franc reportedly have similar susceptibility to powdery mildew infection (34). Seedlings grown from open-pollinated Chardonnay vines were used for inoculum propagation and pathogenicity tests $(10,14,20)$.

Preinoculation exposure of grapevine leaves to acute cold events. Seedlings from stratified seed harvested from openpollinated $V$. vinifera $\mathrm{cv}$. Chardonnay were grown in pots at $22^{\circ} \mathrm{C}$ with a 14-h photoperiod illuminated by daylight-balanced fluorescent bulbs $(5500 \mathrm{~K})$. After 6 weeks of growth, the most ontogenically susceptible leaf, which is generally the second or third leaf below the shoot apex, $\approx 50$ to $75 \%$ expanded and with a noticeably more shiny cuticle than older leaves (9), was detached and surface disinfested in $0.5 \% \mathrm{NaOCl}_{2}$ for $90 \mathrm{~s}$, rinsed twice in distilled water, and incubated overnight at $22^{\circ} \mathrm{C}$ on $1 \%$ water agar plates, adaxial surface upright with petiole inserted into the agar. Cold-temperature treatment levels and durations of each temperature treatment for each experiment are described in the following text. All treatments occurred in the dark and leaves were returned to $22^{\circ} \mathrm{C}$ post treatment.

Inoculum preparation. Conidial inoculum of $E$. necator was cultured on detached seedling leaves on $1 \%$ water agar at $22^{\circ} \mathrm{C}$ with a 14-h photoperiod as mentioned above. Colonies were transferred to new leaves every 14 days to maintain their vigor and ensure that conidia germinated when transferred to host tissue; 10-day-old colonies were used as an inoculum source for all experiments. Germination potential of conidia was assessed immediately before and after each inoculation by transferring a sample of the inoculum to a glass microscope slide. The slide was incubated in a closed petri dish with moist filter paper for $24 \mathrm{~h}$ at $22^{\circ} \mathrm{C}$, after which the percent germination (i.e., presence of a germ tube at least one-half the length of the conidium) was assessed microscopically.

Assessment of initial colony establishment on cold pretreated leaves. Conidial germination, appressorium formation, and primary, secondary, and higher-order branching of hyphae was assessed on inoculated leaves as follows: $24 \mathrm{~h}$ after detached leaves were exposed to an acute cold event of $2,4,6$, or $8^{\circ} \mathrm{C}$ for 2 or $8 \mathrm{~h}$, conidia were dusted onto the upper leaf surface by tapping the lower surface of an inverted, heavily infected seedling leaf suspended $\approx 2 \mathrm{~cm}$ above the leaf to be inoculated. At $48 \mathrm{~h}$ post inoculation (hpi), leaves were fixed overnight in a $3: 1$ glacial acetic acid:95\% ethanol solution, then stored in a 50\% ethanol solution until they could be assessed. To visualize the conidia, leaves were soaked for $30 \mathrm{~s}$ in a staining solution of $1,000 \mathrm{ml}$ of methanol, $800 \mathrm{ml}$ of water, $200 \mathrm{ml}$ of glacial acetic acid, and $60 \mathrm{ml}$ of Commassie Blue filtered working solution, containing $0.25 \mathrm{~g}$ of Commassie Brilliant Blue G (Sigma-Aldrich, St. Louis), $90 \mathrm{ml}$ of $50 \%$ methanol, and $10 \mathrm{ml}$ of glacial acetic acid. After staining, leaves were rinsed in distilled water, soaked in $25 \%$ glycerol for $10 \mathrm{~min}$, and then mounted on glass slides in $50 \%$ glycerol. The first 100 germinated conidia/replication were counted using compound microscopy with $\times 100$ magnification and categorized as (i) germination with appressorium formation, (ii) primary hypha development, or (iii) branched and multiple hyphae. Nongerminated conidia were not counted, because previous research had shown that germination is independent of the nature of the physical characteristics of the substrate $(7,8)$ and the acute cold treatment occurred before inoculation. Three leaves per treatment were used and the experiment was conducted four times. Conidial counts were converted to percent-in-class, because the total counts across each class per replication were 100. Analysis of variance (ANOVA) was used with temperature, duration of exposure, and their interaction as nominal factors for each class of conidial development, which were treated as continuous dependent variables. Significance of the levels of both temperature and duration within each developmental class were compared using least squares mean differences with Tukey's highly significant difference (HSD) (33). In addition, regression analyses treating temperature as a continuous variable and duration as a nominal factor for each conidial developmental class was performed.

Assessment of colony development on cold-pretreated leaves. Colony expansion over a longer period of development was also measured. At $24 \mathrm{~h}$ after detached leaves were exposed to an acute cold event, which consisted of a $2,4,6$ or $8^{\circ} \mathrm{C}$ exposure for 0 (control), 2, 4, 6, or $8 \mathrm{~h}$, they were inoculated using a spore suspension of $10^{5}$ conidia/ml in $0.01 \%$ Tween 20 solution. Ten 5 - $\mu$ l drops were dispensed onto the upper surface of each leaf. The drops were allowed to dry at room temperature for $30 \mathrm{~min}$ before the leaves were returned to incubation at $22^{\circ} \mathrm{C}$. At 5 days postinoculation (dpi), colony diameter was measured under a dissecting microscope by measuring the length of two axial transects through the center of the colony. Total colony area was calculated using the area of a circle $\left(\pi r^{2}\right)$ and the average of the two transects for diameter. This was converted to a percentage of the control treatment. Three replicate leaves were inoculated per treatment and the experiment was conducted four times. Effects of temperature and duration treatments on colony area were analyzed using ANOVA, with temperature and duration as nominal independent factors. Tukey's HSD was used to test for significant differences among levels within each factor. Bartlett's test for homogeneity of variance between the temperature factors at a given duration was used to confirm that pooling of temperature at a given duration could be performed (33).

Comparing detached and attached leaves. As an additional control treatment to ascertain possible artifacts induced by detachment of host leaves, we repeated the above experiment using both detached leaves of $V$. vinifera cv. Cabernet franc and leaves attached to potted whole-plant 5-year-old $V$. vinifera $\mathrm{cv}$. Cabernet franc grapevines. Leaves and whole plants were subject to an acute cold event of $2^{\circ} \mathrm{C}$ for $8 \mathrm{~h}$. Three leaves and three vines (one leaf per vine) were used per treatment, inoculated, and incubated as described above. Control vines were maintained at 22 to $25^{\circ} \mathrm{C}$. Colony diameter was measured on each of three leaves inoculated with a spore suspension as described above. The experiment was conducted twice. The coefficient of variation was calculated for host type (whole plant and detached leaf) and used to compare the magnitude in variation of cold treatments on observed effects. In addition, Student's $t$ test was used to compare the magnitude of the cold-treatment effect on colony size between whole plant and detached leaves.

Transient effects of preinoculation exposure of grapevine leaves to acute cold-temperature events. The most ontogenically susceptible leaves (as described above) of 5-year-old potted $V$. vinifera cv. Cabernet franc vines were collected, surface disinfested, and placed on $1 \%$ water agar plates as described above. Treatments consisted of a single exposure of $2{ }^{\circ} \mathrm{C}$ for $8 \mathrm{~h}$, with controls remaining at $25^{\circ} \mathrm{C}$. At $12,24,36$, or $48 \mathrm{~h}$ post treatment, leaves were either dusted with conidia for development assessment at 48 hpi using the Commassie Blue staining technique as described above or inoculated using a spore suspension to observe effects on colony expansion at $5 \mathrm{dpi}$ as described above. Three replicate leaves were used per experiment, and the 12- and 24-h experiments were repeated twice, while the 36- and 48-h experiments were repeated once. Treatment effects were analyzed using ANOVA and treatment factors were compared with the controls using Dunnett's method (33). 
Effects of acute cold events on in vitro germination and appressorium formation. Conidia of E. necator from freshly sporulating detached leaf cultures were dusted onto glass microscope slides in petri dishes containing moist filter paper to maintain a constant, saturated humidity. The slides were then split into two groups: (i) incubated at $25^{\circ} \mathrm{C}$ for $24 \mathrm{~h}$ and (ii) incubated at $2^{\circ} \mathrm{C}$ for $6 \mathrm{~h}$ and then transferred to $25^{\circ} \mathrm{C}$ for another $18 \mathrm{~h}$. Thereafter, the slides were examined at $\times 400$ magnification and at least 100 conidia/slide were rated for germination (i.e., presence of a germ tube at least one-half the length of the conidium) and presence of an appressorium. Each treatment was replicated on three slides and the experiment repeated. Percent germination was calculated from total observed conidia per slide and standard errors were computed. A Student's $t$ test was performed to determine statistical significance of the treatment effect.

Exposure of nascent mildew colonies to acute cold events. The most ontogenically susceptible leaves (as described above) of 5 -year-old potted $V$. vinifera cv. Pinot noir vines were inoculated using $5-\mu \mathrm{l}$ droplets of a freshly prepared aqueous suspension containing $10^{5}$ conidia/ml and $0.01 \%$ Tween 20 . Ten droplets were placed on the upper surface of each of three leaves of six plants per treatment. Of the six plants per treatment, three were reserved for the assessment of colony development while the remaining three were destructively sampled to assess colony viability. Colonies were allowed to develop for $24 \mathrm{~h}$ in the greenhouse at 22 to $25^{\circ} \mathrm{C}$ with $16 \mathrm{~h}$ of supplemental lighting as described earlier, before exposure to a cold event.

Colonies were exposed to an acute cold-temperature event by placing the potted vines on the floor of a research vineyard at the New York State Agricultural Experiment Station (NYSAES) at Geneva, NY from 3 p.m. to 8 a.m. beginning on 29 April 2008. The experiment was repeated on 1 May 2008. Ambient temperature was recorded every 15 min by a CR10X datalogger (Campbell Scientific, Inc., Logan, UT) located $\approx 1 \mathrm{~km}$ from the site. Control potted vines were maintained in a greenhouse at 22 to $25^{\circ} \mathrm{C}$ with supplemental lighting resulting in a 16 -h photoperiod.

Colonies borne on inoculated leaves of the three vines reserved for assessment of colony development were examined under a dissecting microscope at $\times 16$ while still attached to the potted vines 6 days after inoculation (i.e., 5 days after exposure to an acute cold-temperature event in the vineyard). Colony development was categorized as (i) hyphal growth only. (ii) conidiophores developed but nonsporulating, and (iii) sporulating colony. Student's $t$ test was used to compare the number of colonies from the cold and control treatments that developed in each category. On the three vines reserved for destructive sampling, mortality of hyphae within developing colonies was assessed 4 dpi (i.e., 3 days after exposure to an acute cold-temperature event) by immersing detached leaves in a 1:1000 aqueous dilution of $0.5 \%(\mathrm{wt} / \mathrm{vol})$ fluorescent vital stain fluorescein diacetate (FDA) (Aldrich Chemical Co., Milwaukee, WI). After 3 min, colonies were examined using fluorescence microscopy (325- to 500-nm excitation filter and transmission filter $>530 \mathrm{~nm}$ ) and the percentage of the colony area not exhibiting bright green fluorescence was visually estimated. Mean nonfluorescence between the cold-exposed and control colonies were compared using Student's $t$ test.

The above experiment was repeated under controlled conditions with some modifications. Seedlings were grown from stratified seed harvested from open-pollinated $V$. vinifera $\mathrm{cv}$. Riesling. The most ontogenically susceptible leaves were detached from the seedlings at the petiole, placed onto $1 \%$ (wt/vol) water agar plates, dusted with conidia of E. necator as described above, and incubated at $24^{\circ} \mathrm{C}$. At 2, 3, 4, 5, or $6 \mathrm{dpi}$, selected leaves were moved to a $2^{\circ} \mathrm{C}$ incubator for $8 \mathrm{~h}$ (dark) and returned thereafter to $24^{\circ} \mathrm{C}$. Three replicate leaves were used for each time point. At $24 \mathrm{~h}$ after the end of the acute cold-temperature events, leaves were flooded with FDA and hyphal mortality within 15 colonies was assessed under fluorescence microscopy as described above.
The experiment was repeated five times for those leaves assessed at 2, 3, 4, and 5 dpi and twice for those leaves assessed 6 dpi. Percent colony mortality for both the treated and controls colonies, within each colony age category, was analyzed using Student's $t$ test for mean comparisons because each colony age experiment was conducted at separate times. Colony mortality in the cold treatment within each age category was converted to percent mortality relative to the control by the following equation:

$$
X=(Y-Z) / Y \times 100
$$

where $X=$ percent colony mortality relative to control, $Y=$ percent colony mortality in the cold treatment, and $Z=$ percent colony mortality in the control treatment.

Development of mildew colonies on mature field-grown vines exposed to natural acute cold-temperature events. Experiments were conducted in a vineyard of $V$. vinifera cv. Chardonnay planted in 2004 at NYSAES, wherein vines were inoculated sequentially throughout the growing seasons of 2008 and 2009. Vines were maintained under a calendar spray program to reduce the possibility of natural infection, and leaves were visually inspected for powdery mildew prior to inoculation. If a scheduled spray occurred within 5 days of inoculation, shoot tips were protected from fungicide residue with a food-grade plastic bag during the fungicide application, which allowed emerging tissue to remain free of residual pesticides. The most ontogenically susceptible leaves (see above) were inoculated every 3 to 7 days beginning on 22 May 2008 and 19 May 2009, $\approx 3$ weeks after budbreak in each year, respectively. Ten 5- $\mu$ l drops of a $10^{5}$ conidia/ml suspension were applied to each of 24 leaves per inoculation date. Germination potential of conidial suspensions was assessed on glass slides as described above, and also by placing 5- $\mu \mathrm{l}$ droplets of the conidial suspension on glass slides that were affixed to shoots of the inoculated vines and left to incubate overnight in the vineyard. At $3 \mathrm{dpi}$, three leaves were harvested and colony development and hyphal mortality were assessed as above. Sampling occurred every 3 days until colonies began to develop tertiary branching and conidiophore initials.

Predicted latent period under variable field temperatures (collected hourly, as an average of measurements taken at 15-min intervals) was derived by fitting two linear regression equations to data reported by Delp (7) on the duration of the latent period at various constant growth chamber temperatures:

If $T \leq 10^{\circ} \mathrm{C}$ then $L=1,272-84 \times T$

If $10^{\circ} \mathrm{C}<T<31^{\circ} \mathrm{C}$ then $L=28.68+2839 \times(1 / T)$

where $T=$ average hourly temperature and $L=$ the predicted latent period in hours. The predicted latent period $(L)$ was then transformed to $1 / L$ to represent the total fraction of the period elapsed during an hour at the given temperature. The values of $1 / L$ were summed beginning at the time of inoculation until the sum was $\geq 1$, at which time the predicted latent period was complete. The predicted latent period in hours was then converted to days (rounded to the nearest integer) for comparison to latent periods observed in the above vineyard experiments. Regression analysis was used to compare the difference between observed and predicted latent period values as it relates to the timing of inoculation. When lines appeared to have a classic broken-stick form, the growing season was divided into two groups, (i) budbreak to bloom and (ii) postbloom, and comparisons between average predicted and observed field latent periods were done using Student's $t$ test.

Frequency of occurrence of acute cold-temperature events in diverse viticultural regions. As part of an international research project to assess the impact of climate on heterogeneity of 
grapevine phenology (19), hourly temperature data were collected during the 2005, 2006, and 2007 growing seasons in vineyards in the following locations: Geneva, NY; Davis, CA; Raleigh, NC; Hobart, Tasmania, Australia; Loxton, South Australia, Australia; and Bernkastel, Germany. For the present study, data from each site were reanalyzed to determine (i) the average minimum temperature of the period from budbreak to bloom, calculated from the daily minimum temperatures, and (ii) the mean number of days between budbreak and bloom during which the minimum temperature was $<6^{\circ} \mathrm{C}$.

Disparity between ambient air temperatures and leaf surface temperatures under vineyard conditions. To assess the degree to which leaf surface temperatures differed from ambient air temperatures during the night hours during which acute coldtemperature events occurred, ambient air temperature $2 \mathrm{~cm}$ above the leaf was measured using thermocouples (Omega HH506R thermometer with T-type thermocouples; Omega Engineering, Inc, Stamford, CT) (accuracy of $0.05 \% \pm 0.3^{\circ} \mathrm{C}$ ). Direct measurements of leaf surface temperature were obtained using a M125E Series Portable Infrared Thermometer (Mikron, Oakland, NJ) (accuracy of $1 \% \pm 1{ }^{\circ} \mathrm{C}$ ) held within $50 \mathrm{~cm}$ of the leaf (measuring temperature over a 3 -cm-diameter circle according to the manufacturer's specifications). Temperature measurements were taken at 7:30 p.m. and 5:20 a.m. on 12 to 13,17 to 18 , and 18 to 19 May 2009. Leaf surface temperature was recorded as the mean of three instantaneous readings taken on each of two leaves. Air temperature $2 \mathrm{~cm}$ above the same leaves was recorded as the mean of three instantaneous thermocouple measurements. Cloud coverage was also recorded for each observation date. Differences between leaf surface temperature and ambient air temperature at each time point were compared using Student's $t$ test. Regression analysis of the difference between predicted and observed latent periods versus the minimum low temperature experienced within the first 3 days of development in the field was done to see if the observed differences were due to in-field cold-temperature events during the critical stage of colony development.

Statistical analyses. All statistics beyond mean and standard error calculations were performed using JPM Statistical Software (SAS Institute, Inc., Cary, NC). The "One-Way" analysis in the "Fit Y by X" platform was used for ANOVA, and the "Fit Model" platform with "Standard Least Squares" personality was used for regression analysis.

\section{RESULTS}

Preinoculation exposure of grapevine leaves to acute coldtemperature events. Assessment of initial colony establishment on cold-pretreated leaves. Preinoculation exposure of seedling leaf tissue to acute cold-temperature events affected the development of conidia applied to those leaves compared with the controls. The effects of temperature and treatment duration on colony development were significant for developmental class (i), appressoria only $(P=0.014$ and 0.004 , respectively), and developmental class (iii), branched hyphae ( $P=0.005$ and 0.001 , respectively). There was no interaction effect between temperature and duration ( $P=0.52$ for developmental class [i] and $P=0.61$ for developmental class [iii]). There were no significant effects of temperature, duration, or their interaction on the number of conidia developed to class (ii), primary hyphae $(P=0.12,0.11$, and 0.93 , respectively). A within-effects test of the temperature levels for the developmental classes (i) and (iii) showed that 2 and $8^{\circ} \mathrm{C}$ were significantly different from each other but 4 and $6^{\circ} \mathrm{C}$ were not significantly different from either 2 or $8^{\circ} \mathrm{C}(P>0.05)$. In all cases, the percentage of conidia with appressoria decreased with increasing temperature while the percentage of conidia with branched hyphae increased with increasing temperature. The within-effects test for treatment duration for both developmental classes (i) and (iii) indicated that 2- and 8-h treatments were not significantly different from each other $(P>0.05)$ but were significantly different from the controls $(P<0.05)$. To limit redundancy of presentation, and because the 2-h treatment was more representative of the duration of acute cold-temperature events under field conditions in the early growing season, only the data for the 2-h treatment are shown in Figure 1. Regression analysis, where temperature was treated as continuous rather than nominal, showed that the percentage of germinated conidia that failed to progress beyond the formation of appressoria within 48 hpi was highly correlated with and inversely proportional to the temperature of the preinoculation cold-temperature event (Fig. 1A) $\left(R^{2}=0.99, P=0.006\right.$ for the slope coefficient $)$. A similar relationship was found when the temperature of the preinoculation cold-temperature event was increased from 2 to $8^{\circ} \mathrm{C}$ (Fig. $1 \mathrm{~B})$, where a progressively higher percentage of conidia advanced to form secondary hyphae $\left(R^{2}=0.92, P=0.04\right.$ for the slope coefficient). Exposure to the control temperature $\left(24^{\circ} \mathrm{C}\right)$ resulted in conidial development that was not significantly different from the $8^{\circ} \mathrm{C}$ exposure for all three developmental classes.

Assessment of colony development on cold-pretreated leaves. In a separate experiment to see the longer-term effects of exposure of seedling leaves to acute cold-temperature events prior to inoculation, cold-temperature exposure resulted in a reduction in the relative area of 5-day-old colonies of 37 to 55\% compared with unexposed colonies (Fig. 2). In contrast to the effects on initial colony establishment as described above, ANOVA showed that the degree of suppression of colony area relative to the control was not related to the extent (level of temperature) of the acute cold event (effects test $P=0.41$ for temperature treatment). However, the simple occurrence of a cold event (i.e., duration greater than $0 \mathrm{~h}$ [control] at a given temperature treatment) did significantly affect colony size. The durations of the temperature treatments from 2 to $8 \mathrm{~h}$ were not significantly different from each other according to Tukey's HSD $(P>0.05)$.

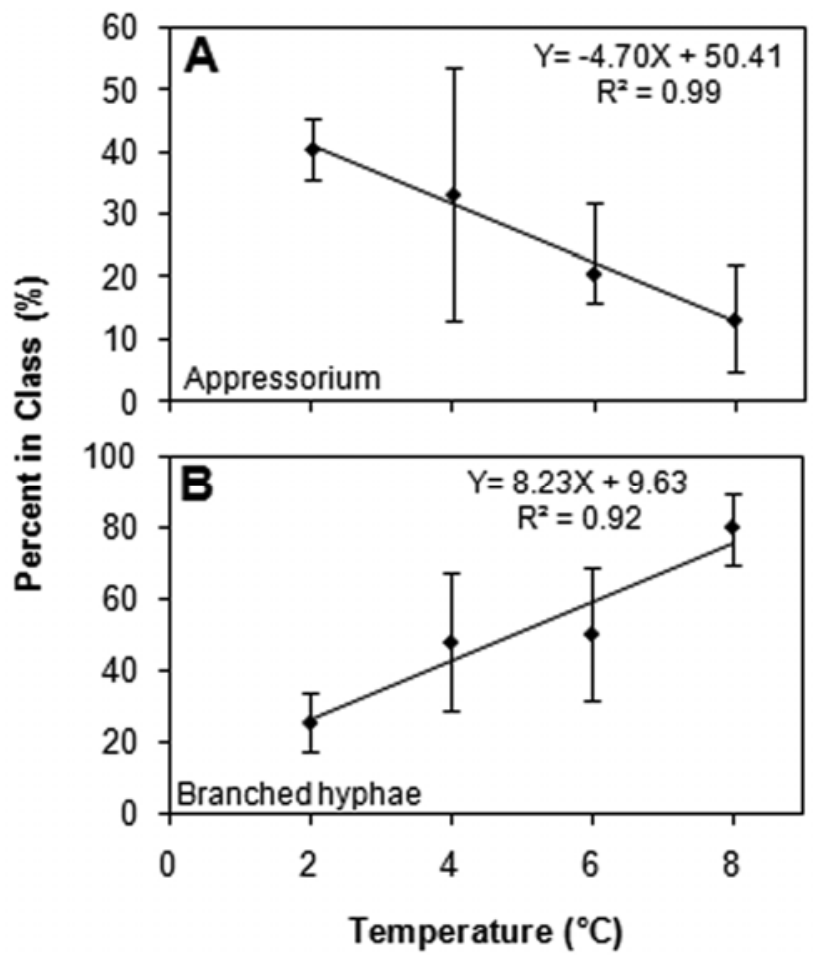

Fig. 1. Effect of cold pretreatment of Vitis vinifera cv. Chardonnay leaves on initial infection by conidia of Erysiphe necator. Detached leaves were exposed to temperatures of 2 to $8^{\circ} \mathrm{C}$ for $2 \mathrm{~h}$ prior to inoculation. Fungal development was assessed $48 \mathrm{~h}$ postinoculation in terms of the percentage of germinated conidia that had progressed no farther than the formation of $\mathbf{A}$, appressorium and $\mathbf{B}$, branched hyphae. 
Comparing detached and attached leaves. The magnitude and variation of the treatment effect was similar between detached leaves and attached leaves on potted $V$. vinifera Cabernet franc when both were exposed to $2^{\circ} \mathrm{C}$ for $8 \mathrm{~h}$ (i.e., colonies that developed on cold-treated detached leaves expanded to $81 \%$ the size of those grown on control leaves with a coefficient of variation [CV] of 0.38 , compared with $77 \%$ with a $\mathrm{CV}$ of 0.42 for colonies on cold-treated attached leaves). The treatment effect on colony size was not statistically different between the detached and attached leaves $(P=0.43)$.

Transient effects of preinoculation exposure of grapevine leaves to acute cold-temperature events. Cold-induced resistance is transient when compared with controls $(P<0.0001$, Dunnett's method), with a maximum treatment effect at $24 \mathrm{~h}$ after the occurrence of a cold treatment. In the assessments at $48 \mathrm{hpi}$, significantly more conidia failed to infect in the 24-h treatment: $26 \%$ of total conidia compared with $11 \%$ in the control treatment $(P=0.007)$. In the other treatments, with inoculations at 12,36 , and $48 \mathrm{~h}, 14,14$, and $13 \%$ of total conidia, respectively, failed to infect, and were not significantly different from the control $(P=$ $0.94,0.94$, and 0.99 , respectively). The 24 -h treatment also had significantly fewer nascent colonies with branched hyphae, 52\% of the total, compared with the $81 \%$ in the control treatment $(P=$ $0.015)$. The other treatments, with 12-, 36-, and 48-h inoculations, had 69,67 , and $72 \%$ of total nascent colonies, respectively, with developed branched hyphae, and were not significantly different than the control treatment $(P=0.56,0.57$, and 0.85 , respectively). Similar results were found when colonies were observed at 5 dpi. The 24- and 36-h inoculation treatments resulted in mean colony areas that were significantly smaller than the controls $(P<0.0001$ and $P=0.0014$, respectively), whereas the $12-$ and 48 -h inoculation treatments resulted in mean colony areas that were not significantly different from the controls $(P=0.53$ and 0.37 , respectively).

Effects of acute cold-temperature events on in vitro germination and appressorium formation. Exposure of conidia on glass slides to a 6-h cold event at $2^{\circ} \mathrm{C}$ had no effect upon subsequent germination or appressoria development. Conidial germination was reduced by $1.24 \%$ (standard error $[\mathrm{SE}]=3.94 \%$ ) and wasn't significantly different from the control $(P=0.75)$, and appressoria formation was reduced by $2.39 \%(\mathrm{SE}=5.00 \%)$ and wasn't significantly different from the control $(P=0.65)$ when exposed to a 6-h cold event.

Exposure of nascent mildew colonies to acute cold-temperature events. In field experiments, the outdoor cold event occurring on 29 to 30 April resulted in significantly fewer colonies in development category (iii), sporulation $(P=0.001)$, and significantly more colonies in development category (i), hyphal growth $(P=0.01)$, at 5 dpi compared with controls. The temperature range over the course of the 29 to 30 April outdoor treatment was 0.0 to $8.5^{\circ} \mathrm{C}$. The outdoor cold event occurring on 1 to 2 May did not result in a significant difference between treatment and control colonies in either development categories (i) or (iii) $(P=0.23$ and 0.59 , respectively). The temperature range over the course of the 1 to 2 May outdoor treatment was 8.4 to $14.0^{\circ} \mathrm{C}$. In both field and controlled-environment studies, mildew colonies exposed to acute cold-temperature events had a significantly greater proportion of the colony that did not hydrolyze FDA (presumed nonviable) than colonies without coldtemperature exposure $(P<0.0001)$ (Fig. 3). In the field, colonies exposed to the overnight cold event of 29 to 30 April 2008 (minimum ambient temperature $=0.0^{\circ} \mathrm{C}$ ) exhibited a mean rate of nonfluorescence of $46.8 \%(\mathrm{SE}=4.1 \%)$ compared with $14.7 \%$ $(\mathrm{SE}=2.7 \%)$ in nonexposed controls, and the cold treatment had a significantly higher level of nonfluorescence $(P<0.0001)$. Those exposed to the overnight cold event of 1 to 2 May 2008 (minimum ambient temperature $=8.4^{\circ} \mathrm{C}$ ) exhibited a mean rate of $61.4 \%(\mathrm{SE}=4.9 \%)$ compared with $28.8 \%(\mathrm{SE}=3.5 \%)$ in nonexposed controls, and the cold treatment had a significantly higher level of nonfluorescence $(P<0.0001)$.

In controlled-environment studies, the effects of an acute coldtemperature $\left(2^{\circ} \mathrm{C}\right)$ event of $8 \mathrm{~h}$ on nascent mildew colonies ranging in age from 2 to 6 days old were only significant on 3-day-old colonies. Although the other age categories trended toward reduced fluorescence in the cold treatment, they were not statistically different from their respective controls (Table 1).

Development of mildew colonies on mature field-grown vines exposed to natural acute cold-temperature events. When the differences between actual and predicted latent periods was regressed against climate day (where calendar day numbering starts on $1 \mathrm{March}$ ), the slope was significantly different from zero $(P=0.02)$. Observations were then divided into two groups: (i) budbreak to bloom and (ii) post bloom. Latent periods following inoculations performed during the period between budbreak and bloom (climate day 62 to 107 ), were $75 \%$ longer than predicted by equations 2 and $3(P=0.0006)$, whereas latent periods following inoculations between bloom and veraison were $30 \%$ longer than predicted $(P=0.04)$ (Fig. 4). The magnitude of the disparity between observed and predicted latent period was significantly correlated $(P<0.0001)$ with the minimum temperature that occurred within 3 dpi (Fig. 5). Colonies that were 3 days old on 31 May 2009, when overnight temperatures dropped below $5^{\circ} \mathrm{C}$ for $8 \mathrm{~h}$, had not sporulated when observations were terminated 24 days later, although the predicted latent period for this cohort of colonies was only 8 days. Similarly, colonies resulting from inoculations made 2 days after this same cold event did not sporulate until $20 \mathrm{dpi}$, or 13 days after the end of the latent period predicted for this cohort of colonies.

Frequency of occurrence of early-season cold-temperature events in diverse viticultural regions. Across a broad range of climates in the northern and southern hemispheres, overnight low temperatures in vineyards fell below $6^{\circ} \mathrm{C}$ an average of 14 to 21 times between budbreak and bloom (Table 2). The average overnight minimum temperature for the period delimited by the above phenological stages ranged from $6.0^{\circ} \mathrm{C}$ at Hobart, Tasmania to $10.2^{\circ} \mathrm{C}$ at Raleigh, NC (Table 2). Although the average low overnight temperature was higher at Loxton, South Australia $\left(8.9^{\circ} \mathrm{C}\right)$ than at Geneva, NY $\left(7.1^{\circ} \mathrm{C}\right)$, both sites experienced an average of 17 nights when temperatures fell below $6^{\circ} \mathrm{C}$ (Table 2).

Disparity between ambient air temperatures and leaf surface temperatures under vineyard conditions. In all overnight measurements, the temperature of the leaf surface was substantially and significantly $(P=0.05$ to $<0.0001)$ below that of

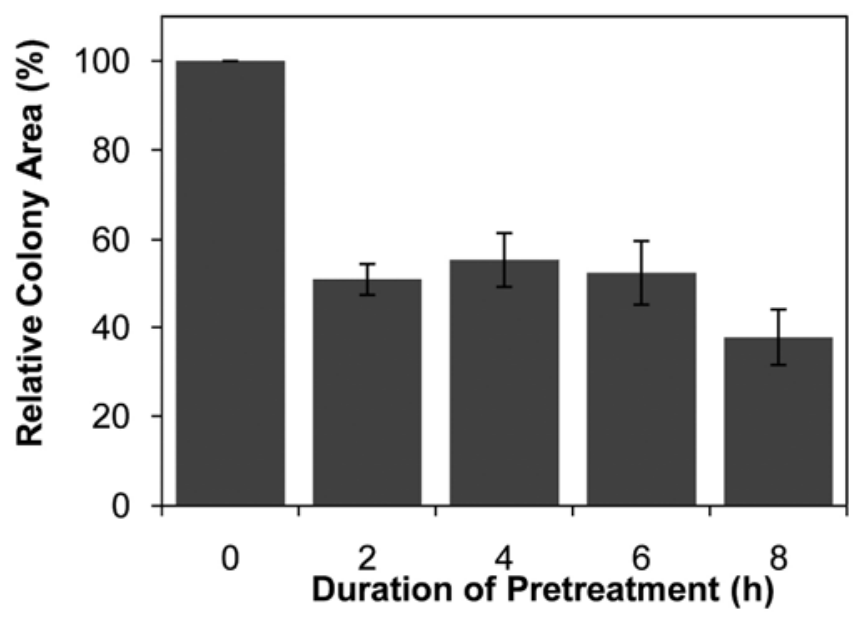

Fig. 2. Effect of preinoculation cold treatment of Vitis vinifera cv. Chardonnay leaves on subsequent Erysiphe necator colony development at 5 days postinoculation. Colony area was expressed as percent of the control treatment $(0 \mathrm{~h})$, and data were pooled across all temperature treatments from 2 to $8^{\circ} \mathrm{C}$. 
the air $2 \mathrm{~cm}$ above the leaf (Table 3 ). The differential between the leaf surface and air temperature ranged from -0.9 to $-7.6^{\circ} \mathrm{C}$ (Table 3). The differences between leaf surface and air temperatures $\left(-3.8\right.$ to $\left.-7.6^{\circ} \mathrm{C}\right)$ were greatest at $7: 30$ p.m. compared with $5: 20$ a.m. on all 3 days (Table 3 ). This was $\approx 1 \mathrm{~h}$ before sunset on the dates of observation, although differences of -3.0 and $-3.4^{\circ} \mathrm{C}$ were observed at 5:20 a.m., $\approx 30$ min before sunrise on the dates of observation (Table 3). Temperature differentials of approximately the same magnitude were recorded under both clear and overcast conditions, and under calm conditions and in the presence of light wind (Table 3 ).

\section{DISCUSSION}

Leaves that were normally ontogenically susceptible yielded a more resistant phenotype when exposed to an acute cold-temperature event. Exposure of grapevines to acute cold-temperature events affected several fitness parameters and was deleterious to the development of powdery mildew epidemics at multiple levels.
Infection efficiency (ability of a conidium to progress beyond appressorium within $48 \mathrm{~h}$ of arrival on the host) was reduced, resulting in the development of fewer colonies from a given number of germinated conidia. Radial expansion of colonies was slowed (i.e., smaller colonies at $5 \mathrm{dpi}$ on cold-pretreated leaves). Within established colonies, individual hyphal segments died, thereby reducing colony density. Finally, the field latent period was lengthened, in some cases more than doubled, in association with acute cold-temperature events occurring early in the growing season. The foregoing pathogen responses were similar to those reported to occur during the transition of ontogenically susceptible grape berries to a resistant state as they age $(11,12,15$, $16,18,23$ ) (e.g., conidia placed upon ordinarily susceptible leaves previously exposed to acute cold-temperature events produced a phenotypic response that would commonly be observed on ontogenically resistant berries).

Exposure of grape leaves to an acute cold-temperature event before inoculation reduced the percentage of germinated conidia that were able to form hyphae beyond a germ tube. This is a
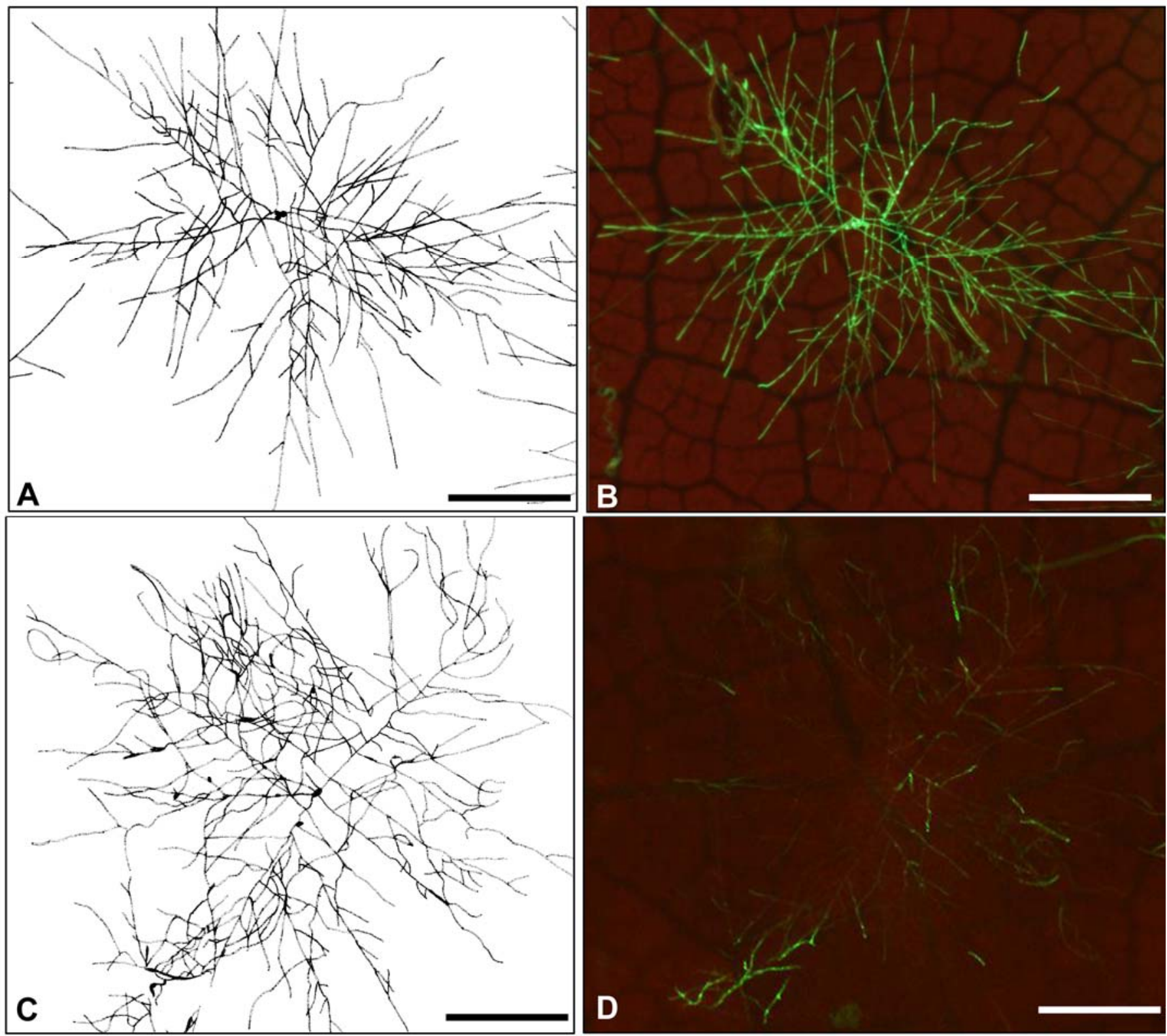

Fig. 3. Line sketches and vital staining of 4-day-old Erysiphe necator colonies growing on detached Vitis vinifera cv. Chardonnay leaves under controlled conditions. A, Line sketch of a colony grown at a constant optimum temperature of $24^{\circ} \mathrm{C} ; \mathbf{B}$, the same colony stained with fluorescein diacetate (FDA) and exposed to UV light; $\mathbf{C}$, line sketch of a colony grown at $24^{\circ} \mathrm{C}$ save for acute exposure to $2^{\circ} \mathrm{C}$ for $8 \mathrm{~h}$ at 3 days postinoculation; and $\mathbf{D}$, the same cold-treated colony stained with FDA and exposed to UV light. Lack of fluorescence is an indirect assessment of mortality. Scale bars are $50 \mu \mathrm{m}$. 
prepenetration-like resistance phenotype seen in grape berries $(13,23)$ and appears to be the consequence of an occurrence but not the duration of cold pretreatment. We also observed that this cold-induced resistance was transitory, with the greatest resistance response occurring between 24 and $36 \mathrm{~h}$ after a low, nonfreezing temperature event. This transitory response may be associated with a number of equally ephemeral responses of plants to acute cold (43).

In contrast to the effects of cold treatment on initial colony establishment, effects upon colony expansion were still apparent at 5 dpi (6 days after cold pretreatment). The occurrence of a cold-temperature event alone was sufficient to elicit a significant treatment effect independent of the degree or duration of such an event (Fig. 2). Unlike the foregoing studies on conidial germination, colonies were established by a method that deposited a concentrated dose of inoculum (a 5- $\mu$ l droplet containing 500 conidia), thereby increasing the probability of establishment at any given point. The different results with respect to duration and intensity of cold-temperature events among germlings compared with colonies are not necessarily contradictory. In the studies on germinated conidia, spores were dusted onto the tissue and were widely separated. Thus, in the case of the germinated spores, we recorded the effects of acute cold-temperature events upon the success or failure of individual conidia development, whereas establishment of a colony was a near certainty due to the quantity of inoculum deposited using the conidial suspensions. Thus, the responses are not directly comparable.

Nascent colonies directly exposed to acute low-temperature events exhibited higher mortality among hyphal strands within

TABLE 1. Percent mortality (nonfluorescence) in young Erysiphe necator colonies on Vitis vinifera cv. Riesling exposed to an acute cold temperate $\left(2^{\circ} \mathrm{C}\right.$ for $8 \mathrm{~h})^{\mathrm{a}}$

\begin{tabular}{|c|c|c|c|c|}
\hline \multirow[b]{2}{*}{ Timing $(\mathrm{dpi})^{\mathrm{b}}$} & \multicolumn{2}{|c|}{ Total colony mortality } & \multirow[b]{2}{*}{ Mortality $(\%)^{\mathrm{c}}$} & \multirow[b]{2}{*}{$P^{\mathrm{d}}$} \\
\hline & Control (\%) & Cold treated $(\%)$ & & \\
\hline 2 & $50.5(8.5)$ & $57.1(18.7)$ & 11.6 & 0.71 \\
\hline 3 & $20.6(7.7)$ & $61.5(4.3)$ & 66.7 & 0.005 \\
\hline 4 & $20.3(10.1)$ & $47.4(3.9)$ & 57.2 & 0.07 \\
\hline 5 & $22.5(9.2)$ & $44.9(8.8)$ & 49.9 & 0.13 \\
\hline 6 & $43.7(2.2)$ & $64.4(13.0)$ & 32.1 & 0.16 \\
\hline
\end{tabular}

a Standard error in parenthesis.

b Timing of cold exposure measured as days post inoculation (dpi).

c Mortality relative to controls calculated as percent increase in mortality relative to controls [(cold treated - control $) /$ cold treated $\times 100]$.

d Student's $t$ value comparing mean colony mortality for cold-treated and control colonies at each development stage.

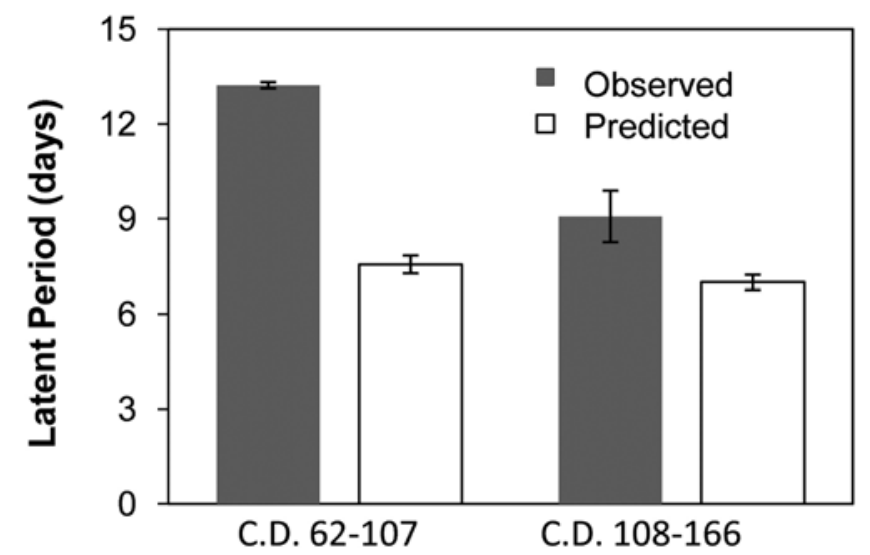

Fig. 4. Observed and predicted latent periods of Erysiphe necator on fieldgrown Vitis vinifera cv. Chardonnay in 2008 and 2009 relative to climate day (day $1=1 \mathrm{March}$ ). Observed latent period is the time from inoculation to first sporulation; predicted latent period was derived from equations 2 and 3 using hourly weather data. colonies (Table 1; Fig. 3). This result is similar to that reported for damage rendered by exposure to high temperatures and ultraviolet radiation $(4,7,49)$, as well as development of ontogenic resistance $(11,12,15,16,18,23)$. The lack of ability in the 2- and 6-dpi controls to hydrolyze FDA was likely an artifact of the FDA staining process on very young or aging colonies: slow growth and metabolism can result in reduced fluorescence $(28,41)$. Although the same could be said for the cold-treated colonies, reduced fluorescence as a result of cold exposure when compared with controls indicated that this acute cold stress was reducing the metabolic activity of the nascent colony. In the present study, a statistically significant reduction in fluorescence was observed when 3-day-old colonies were exposed to acute cold-temperature events. This is a particularly critical stage in the development of a powdery mildew colony because, under the optimal temperature conditions used before and after acute cold-temperature exposure, the 3-day-old colonies would be in transition from vegetative growth to reproductive development (7). Furthermore, in vineyards, the magnitude of the disparity between expected and observed latent period was correlated with the occurrence of acute cold-temperature events within 3 days after inoculation (Fig. 5). Whereas previously described temperature relationships treated low, nonfreezing temperatures (temperatures $<10^{\circ} \mathrm{C}$ ) as nonkilling $(7,36)$, our data showed that acute low-temperature events have a clear negative impact upon the pathogen.

Low, nonfreezing temperatures are known to retard developmental processes in plants, alter source/sink relationships, reduce

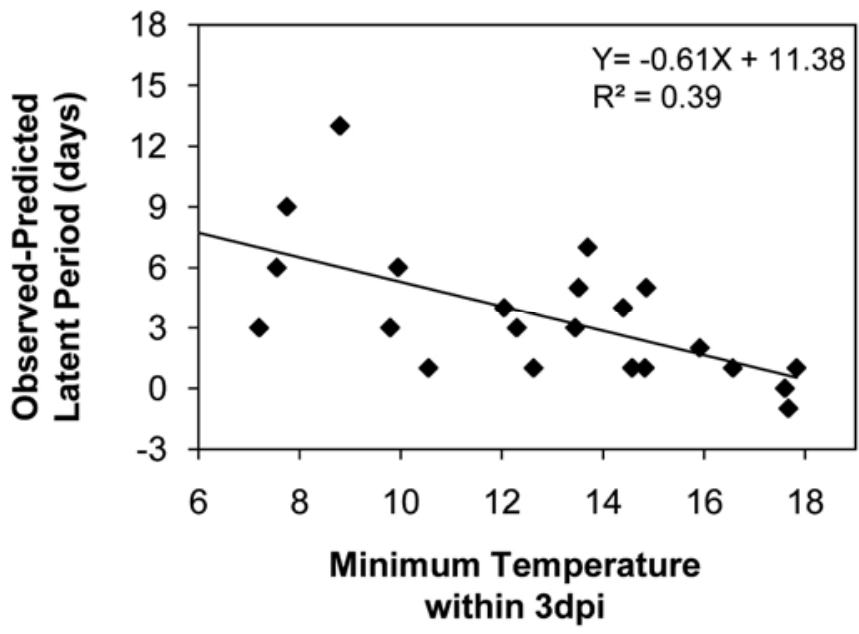

Fig. 5. Difference in observed versus predicted latent period for Erysiphe necator on Vitis vinifera cv. Chardonnay as it relates to the minimum temperature experienced in the field within 3 days postinoculation. Observed latent period was the time between inoculation and first sporulation; predicted latent period was derived from hourly temperature measurements using equations 2 and 3 in the text.

TABLE 2. Summary of overnight cold-temperature events between budbreak and bloom occurring in six viticulture regions around the world

\begin{tabular}{llcc}
\hline Site & \multicolumn{1}{c}{ Climate type } & Temperature $\left({ }^{\circ} \mathrm{C}\right)^{\mathrm{a}}$ & Days $^{\mathrm{b}}$ \\
\hline Geneva, NY & Cool temperate & 7.1 & 17 \\
Hobart, Tasmania & Maritime & 6.0 & 21 \\
Davis, CA & Mediterranean & 7.6 & 16 \\
Bernkastle, Germany & Northern temperate & 7.5 & 18 \\
Loxton, South Australia & Mediterranean/desert & 8.9 & 17 \\
Raleigh, NC & Warm temperate & 10.2 & 14 \\
\hline
\end{tabular}

a Average daily minimum temperature of the period between budbreak and bloom.

${ }^{b}$ Days between budbreak and bloom with minimum temperatures $\leq 6^{\circ} \mathrm{C}$; integer average of period from budbreak to bloom for 2005 to 2007 inclusive. 
carbon assimilation (26), alter stomatal behavior (49), increase ethylene production resulting in dwarfing (27), and reduce vigor (6). Substantial work done in Arabidopsis on the response to cold temperatures has shown that cold-stress response is often similar to other stress and water-relation responses (Thomashow provides an excellent review [43]), and recent work has implicated the involvement of the salicylic acid (SA) pathway in response to chilling (46). In grape, exogenous application of SA appears to induce cold tolerance (45). Near-freezing temperatures also are associated with increased resistance to a variety of pathogens of grasses, including snow molds $(1,22)$, Bipolaris sorokiniana on barley (35), and Puccinia poae-nemoralis on bluegrass (44). With respect to $E$. necator on grapevine, reduced vigor and host stress is generally associated with attenuated growth of the biotrophic pathogen and reduced disease severity $(3,34)$. Thus, the impact of acute low-temperature events may be exerted through either or both of the following: (i) a deleterious effect of acute low temperatures on host growth and development that makes tissues of lower quality as a substrate for pathogen growth or (ii) triggering or enhancement of biochemical pathways associated with stress and disease resistance, particularly in rapidly developing young tissues. What distinguishes our study from most of the foregoing is that the responses we noted appear to be transient and, to some degree, reversible. The increased resistance of young leaves reported here for $V$. vinifera seedlings is not due to repeated or prolonged exposure to gradually decreasing temperatures associated with winter dormancy. The phenomena we observed in our field studies were associated with punctuated, random events during what typically spans the postdormancy period for temperate woody plants. This is when they generally are considered to be losing their frost/freezing resistance (25) and are the most susceptible to frost damage. Although the genetics of cold acclimation and chilling/freezing stress in grapevine have been investigated $(21,42)$, we are not aware of previous reports indicating that chilling stress functions as an inducer of resistance to powdery mildew.

A substantial increase of host resistance due to acute coldtemperature events was demonstrated in our preinoculation studies. Our postinoculation studies were not designed to separate the direct effects of treatments on the pathogen from those exerted through the host. It will be challenging to definitively separate direct and possibly deleterious effects of acute cold temperatures on an established biotrophic pathogen from effects caused by cold-induced changes in host susceptibility. However, the results of our preinoculation experiments and the lack of an effect of acute cold-temperature events on in vitro germination and appressorium formation, together with previous studies, cumulatively suggest that a resistance response in the host could be responsible for a major proportion of the observed effect on nascent colonies. In the vegetative state, E. necator survives freezing temperatures within overwintering grapevine buds (34). E. necator colonies on grape seedlings in vitro can survive for months at $4^{\circ} \mathrm{C}$ and can produce conidia and ascocarps (14). Admittedly, prolonged cold temperatures may have a fundamentally different effect on the pathogen (and host) compared with the transitory cold events with intervening warm periods that typify acute cold-temperature events under vineyard conditions. However, we propose that the primary effects of acute cold-temperature events are exerted through enhanced resistance of tissues that are normally highly susceptible to infection.

Temperature is the environmental parameter most universally applied to forecast the development of grapevine powdery mildew $(5,24,36)$. However, our findings suggest that low, nonfreezing temperatures should be taken into greater account than current literature suggests. Some models adjust for low, nonfreezing temperatures but either do not treat them as a negative influence on powdery mildew development (36) or classify temperatures of 0 to $15^{\circ} \mathrm{C}$ as having similar impacts on development (5). Other models assume temperature responses to be instantaneous and without future effect (37), whereas our data suggest that suboptimal temperature events can affect future development of epidemics. The Gubler-Thomas model (24) does take into effect cooler daytime temperatures and their impact on risk assessment by requiring the satisfaction of six or more continuous hours at 21 to $30^{\circ} \mathrm{C}$ in order to initiate the risk index (with an additional requirement for these conditions to be met for three consecutive days) or to maintain risk index values. However, it does not account for punctuated acute cold events that can occur during a 24-h period when daytime temperatures may fall into the optimal development range and, thus, satisfy the model requirements. The aforementioned acute cold events would be treated as neutral by the Gubler-Thomas model. Our data suggest that cold events should not be considered neutral but should be taken to have an effect on powdery mildew development similar to that of acute high temperatures $(4,7,24)$. Acute cold-temperature events cause a previously unaccounted-for effect that could substantially alter how forecasting systems treat the early-season development of an epidemic.

Our review of climate data demonstrates that acute low-temperature events are neither rare nor restricted to otherwise cool climates; in fact, they occur with substantial regularity in what are generally regarded as some of the warmest viticultural regions (Table 2). Additionally, we found that acute cold-temperature events are probably more severe in the field than indicated by ambient air temperatures, because ambient night air was substantially warmer than leaf surfaces due to radiational cooling of leaves (Table 3 ). In previous studies of epidemic progress in grape powdery mildew, several phenomena have been noted that might be related to the occurrence of acute cold-temperature events. Gadoury et al. (17) noted that prebloom development of foliar mildew was typified by increased incidence, without a commensurate increase in severity measured as colony size or infected leaf area (i.e., colonies failed to expand despite favorable temperature conditions that existed in the vineyard). In a study of incidence-severity relationships, Seem (39) reported that foliar severity of grapevine powdery mildew remained both low and nearly constant (i.e., near $1 \%$ ) regardless of initial incidence levels until foliar incidence exceeded a critical level of 10 to $20 \%$, which occurred after bloom in each year of the study. Collec-

TABLE 3. Leaf surface and air temperature in a vineyard of Vitis vinifera cv. Chardonnay $\approx 2$ weeks after budbreak at Geneva, NY

\begin{tabular}{|c|c|c|c|c|c|c|}
\hline Date & Time $^{\mathrm{a}}$ & Leaf $\left({ }^{\circ} \mathrm{C}\right)^{\mathrm{b}}$ & $\operatorname{Air}\left({ }^{\circ} \mathrm{C}\right)^{\mathrm{b}}$ & $\Delta T\left({ }^{\circ} \mathrm{C}\right)^{\mathrm{c}}$ & Cloud cover & Wind speed $(\mathrm{km} / \mathrm{h})$ \\
\hline \multirow[t]{2}{*}{ 12-13 May } & 7:30 p.m. & $13.0(1.4)$ & $16.8(0.6)$ & $-3.8(P<0.0001)$ & Clear & 0 \\
\hline & 5:20 a.m. & $0.5(0.2)$ & $3.5(0.1)$ & $-3.0(P<0.0001)$ & Clear & 0 \\
\hline 17-18 May & 7:30 p.m. & $5.7(1.9)$ & $11.3(0.0)$ & $-7.6(P=0.002)$ & Clear & 0 \\
\hline \multirow[t]{2}{*}{ 18-19 May } & 7:30 p.m. & $4.8(2.1)$ & $11.4(0.4)$ & $-6.6(P=0.002)$ & Clear & 0 \\
\hline & 5:20 a.m. & $-1.7(0.5)$ & $1.7(0.1)$ & $-3.4(P<0.0001)$ & Clear & 0 \\
\hline
\end{tabular}

\footnotetext{
a Times of measurements were approximately $1 \mathrm{~h}$ before sunset and $30 \mathrm{~min}$ before sunrise.

b Temperature as indicated by infrared remote sensing of leaf surface or a thermocouple located $2 \mathrm{~cm}$ above the leaf surface. Values in parenthesis are standard errors of the mean.

${ }^{\mathrm{c}}$ Difference between leaf surface temperature and air temperature $2 \mathrm{~cm}$ above leaf surface. Values in parentheses indicate significance by Student's $t$ test.
} 
tively, this suggests that acute cold-temperature events may suppress the early-season spread of grapevine powdery mildew, and that present forecasting systems could benefit from modeling this effect.

Our study highlights the impact that a single abiotic stress can have on the development of a biotrophic pathogen. Abiotic stresses such as drought, salt, and heat have been reported to reduce host susceptibility in other powdery mildew pathosystems $(38,47,48)$. Although we have experimentally examined the impact of single acute cold-temperature events, in practice, these events occur repeatedly and their effect could be additive over a period of days or weeks. Furthermore, we have experimentally dealt with ontogenically susceptible tissues but, under field conditions, all aboveground tissues of the host could be affected. Thus, the effects of acute cold-temperature events might also act in an additive fashion with the already substantial resistance of older foliage and fruit. In continued research, we will investigate both the mechanisms involved in acute cold-temperature-induced resistance to E. necator, and the possible impact of acute coldtemperature events on other grapevine pathogens.

\section{ACKNOWLEDGMENTS}

This research was supported by the United States Department of Agriculture Viticulture Consortium-East, The Pennsylvania Wine Marketing Board, the New York Wine and Grape Foundation, the American Society for Enology and Viticulture National and Eastern Sections, and the American Wine Society. The South Australian Research and Development Institute and the Commonwealth Science and Industry Research Organization hosted M. M. Moyer as a visiting scholar twice in 2007 and 2008. The research described herein represents a portion of a dissertation submitted by M. M. Moyer to the Graduate School of Cornell University in partial fulfillment of requirements for the Ph.D. in Plant Pathology. We thank J. Runner, A. Norris, and M. J. Welser for their excellent technical assistance; and M. Maixner (Biologische Bundesanstalt), K. Evans (University of Tasmania), T. B. Sutton (North Carolina State University), and W. D. Gubler (University of California-Davis) for their assistance in providing weather data.

\section{LITERATURE CITED}

1. Arsvoll, K. 1977. Effects of hardening, plant age and development in Phleum pratence and Festuca pratensis on resistance to snow mould fungi. Meld. Nor. Landbrukshoegsk. 56:1-14.

2. Austin, C. N., Lakso, A. N., Seem, R. C., Riegel, D. G., Grove, G. G., and Wilcox, W. F. 2009. Inhibition of grapevine powdery mildew by improved vineyard sunlight exposure. (Abstr.) Phytopathology 99:S6.

3. Calonnec, A., Cartolaro, P., and Chadoeuf, J. 2009. Highlighting features of spatiotemporal spread of powdery mildew epidemics in the vineyard using statistical modeling on field experimental data. Phytopathology 99:411-422.

4. Chellemi, D. O., and Marois, J. J. 1991. Sporulation of Uncinula necator on grape leaves as influenced by temperature and cultivar. Phytopathology 81:197-201.

5. Chellemi, D. O., and Marois, J. J. 1991. Development of a demographic growth model for Uncinula necator by using a microcomputer spreadsheet program. Phytopathology 81:250-254.

6. Colhoun, J. 1973. Effects of environmental factors on plant disease. Annu. Rev. Phytopathol. 11:343-364.

7. Delp, C. J. 1954. Effect of temperature and humidity on the grape powdery mildew fungus. Phytopathology 44:615-626.

8. Diehl, H., and Heintz, C. 1987. Studies on the generative reproduction of grapevine powdery mildew (Uncinula necator Berk.). Vitis 26:114-122.

9. Doster, M. A., and Schnathorst, W. C. 1985. Effects of leaf maturity and cultivar resistance on development of the powdery mildew fungus on grapevines. Phytopathology 75:318-321.

10. Falk, S. P., Gadoury, D. M., Pearson, R. C., and Seem, R. C. 1995. Partial control of grape powdery mildew by the mycoparasite Ampelomyces quisqualis. Plant Dis. 79:483-490.

11. Ficke, A., Gadoury, D. M., and Seem, R. C. 2002. Ontogenic resistance and plant disease management: a case study of grape powdery mildew. Phytopathology 92:671-675.

12. Ficke, A., Gadoury, D. M., Seem, R. C., and Dry, I. B. 2003. Effects of ontogenic resistance upon establishment and growth of Uncinula necator on grape berries. Phytopathology 93:556-563.

13. Ficke, A., Gadoury, D. M., Seem, R. C., Godfrey, D., and Dry, I. B. 2004. Host barriers and responses to Uncinula necator in developing grape berries. Phytopathology 94:438-444.

14. Gadoury, D. M., and Pearson, R. C. 1991. Heterothallism and pathogenic specialization in Uncinula necator. Phytopathology 81:1287-1293.

15. Gadoury, D. M., Seem, R. C., Ficke, A., and Wilcox, W. F. 2001. The epidemiology of powdery mildew on Concord grapes. Phytopathology 91:948-955.

16. Gadoury, D. M., Seem, R. C., Ficke, A., and Wilcox, W. F. 2003. Ontogenic resistance to powdery mildew in grape berries. Phytopathology 93:547-555.

17. Gadoury, D. M., Seem, R. C., Magarey, P. A., Emmett, R., and Magarey, R. 1997. Effects of environment and fungicides on epidemics of grape powdery mildew: considerations for practical model development and disease management. Vitic. Enol. Sci. 52:225-229.

18. Gadoury, D. M., Seem, R. C., Wilcox, W. F., Henick-Kling, T., Conterno, L., Day, A., and Ficke, A. 2007. Effects of diffuse colonization of grape berries by Uncinula necator on bunch rots, berry microflora, and juice and wine quality. Phytopathology 97:1356-1365.

19. Gadoury, D. M., Seem, R. C., Wilcox, W. F., Kennelly, M. M., Magarey, P. A., Dry, I. B., Gubler, W. D., Pscheidt, J. W., Grove, G. G., Sutton, T. B., Ellis, M. A., Stevenson, K. L., Maixner, M., and Evans, K. J. 2006. Modeling and mapping the relationship between climate and ontogenic resistance to the major fungal disease of grapevine. Paper presented at the 5th International Workshop on Grapevine Downy and Powdery Mildew, Istituto Agrario di San Michele all'Adige, Italy.

20. Gadoury, D. M., Wakefield, L. M., Seem, R. C., Cadle-Davidson, L., and Dry, I. B. 2004. Preliminary studies of signaling and sporulation in Uncinula necator. (Abstr.) Phytopathology 94:S33.

21. Garris, A. J., Clark, L., Owens, C. L., McKay, S., Luby, J., Matthiason, K., and Fennel, A. 2009. Mapping of photoperiod induced growth cessation in the wild grape Vitis riparia Michx. using microsatellite markers. J. Am. Hortic. Sci. 134:261-272.

22. Gaudet, D. A., Laroche, A., Frick, M., Davoren, J., Puchalski, B., and Ergon, A. 2000. Expression of plant defence related (PR-protein) transcripts during hardening and dehardening of winter wheat. Physiol. Mol. Plant Pathol. 57:15-24.

23. Gee, C. T., Gadoury, D. M., and Cadle-Davidson, L. 2008. Ontogenic resistance to Uncinula necator varies by genotype and tissue type in a diverse collection of Vitis spp. Plant Dis. 92:1067-1073.

24. Gubler, W. D., Smith, R. J., Varela, L. G., Vasquez, S. J., Stapleton, J. J., Purcell, A. H., and Leavitt, G. M. 2009. UC IPM Pest Management Guidelines: Grape. Univ. Calif. ANR Publ. 3448.

25. Guy, C. L. 1990. Cold acclimation and freezing stress tolerance: role of protein metabolism. Annu. Rev. Plant Physiol. Plant Mol. Biol. 41:187223.

26. Hallgren, J. E., and Oquist, G. 1990. Adaptations to low temperatures. Pages 265-293 in: Stress Responses in Plants: Adaptation and Acclimation Mechanisms, Vol. 12. R. G. Alscher and J. R. Cumming, eds. Wiley-Liss, Inc., New York.

27. Huang, J. Y., and Lin, C. H. 2003. Cold water treatment promotes ethylene production and dwarfing in tomato seedlings. Plant Physiol. Biochem. 41:284-288.

28. Ingham, E. R., and Klein, D. A. 1982. Relationship between fluorescein diacetate-stained hyphae and oxygen utilization, glucose utilization and biomass of submerged fungal batch cultures. Appl. Environ. Microbiol. 44:363-370

29. Kast, W. K. 1997. A step by step risk analysis (SRA) used for planning sprays against powdery mildew (OiDiag-System). Vitic. Enol. Sci. 52:230-231.

30. Moyer, M. M., Gadoury, D. M., Dry, I. B., Cadle-Davidson, L., and Seem, R. C. 2009. Effects of low temperature events on host susceptibility and on infection, colony development and survival of Erysiphe necator. (Abstr.) Phytopathology 99:S89.

31. Moyer, M. M., Gadoury, D. M., Seem, R. C., and Wilcox, W. F. 2007. Towards an advisory system for grapevine powdery mildew in cooler climates. (Abstr.) Phytopathology 97:S80.

32. Moyer, M. M., Gadoury, D. M., Wilcox, W. F., and Seem, R. C. 2008. Development of an advisory system for grapevine powdery mildew in eastern North America: a reassessment of epidemic progress. (Abstr.) Phytopathology 98:S190.

33. Ott, R. L., and Longnecker, M. 2001. An Introduction to Statistical Methods and Data Analysis, 5th ed. Duxbury, Pacific Grove, CA.

34. Pearson, R. C., and Gadoury, D. M. 1992. Powdery mildew of grape. Pages 129-146 in: Plant Diseases of International Importance, Vol. 3. J. Kumar, H. S. Chaube, U. S. Singh, and A. N. Mukhopadhyay, eds. Prentice Hall, Englewood Cliffs, NJ.

35. Rapacz, M., Plazek, A., and Niemczyk, E. 2000. Frost de-acclimation of barley (Hordeum vulgare L.) and meadow fescue (Festuca pratensis 
Huds.): relationship between soluble carbohydrate content and resistance to frost and the fungal pathogen Bipolaris sorokiniana (Sacc.) Shoem. Ann. Bot. 86:539-545.

36. Sall, M. A. 1980. Epidemiology of grape powdery mildew: a model. Phytopathology 70:338-342.

37. Schnathorst, W. C. 1965. Environmental relationships in the powdery mildews. Annu. Rev. Phytopathol. 3:343-366.

38. Schweizer, P., Vallélian-Bindschedler, L., and Mösinger, E. 1995. Heatinduced resistance in barley to the powdery mildew fungus Erysiphe graminis f. sp hordei. Physiol. Mol. Plant Pathol. 47:51-66.

39. Seem, R. C. 1984. Disease incidence and severity relationships. Annu. Rev. Phytopathol. 22:133-150.

40. Smart, R. E. 1985. Principles of grapevine canopy microclimate manipulations with implications for yield and quality: a review. Am. J. Enol. Vitic. 36:230-239.

41. Söderdström, B. E. 1977. Vital staining of fungi in pure cultures and in soil with fluorescein diacetate. Soil Biol. Biochem. 9:59-63.

42. Tattersall, E. A. R., Grimplet, J., DeLuc, L., Wheatley, M. D., Vincent, D., Osborne, C., Ergul, A., Lomen, E., Blank, R. R., Schlauch, K. A., Cushman, J. C., and Cramer, G. R. 2007. Transcript abundance profiles reveal larger and more complex responses of grapevine to chilling compared to osmotic and salinity stress. Funct. Integr. Genomics 7:317-333.
43. Thomashow, M. F. 1999. Plant cold acclimation: freezing tolerance genes and regulatory mechanisms. Annu. Rev. Plant Physiol. Plant Mol. Biol. 50:571-599.

44. Tronsmo, A. M. 1984. Resistance to the rust fungus Puccinia poaenemoralis in Poa preatensis induced by low-temperature hardening. Can. J. Bot. 62:2891-2892.

45. Wang, L.-J., and Li, S.-H. 2006. Salicylic acid-induced heat or cold tolerance in relations to $\mathrm{Ca} 2+$ homeostasis and antioxidant systems in young grape plants. Plant Sci. 170:685-694.

46. Wang, Y., and Hua, J. 2009. A moderate decrease in temperature induces COR15a expression through the CBF signaling cascade and enhances freezing tolerance. Plant J. 60:340-349.

47. Wiese, J., Kranz, T., and Schubert, S. 2004. Induction of pathogen resistance in barley by abiotic stress. Plant Biol. 6:529-536.

48. Wiese, J., Wiese, H., Schwartz, J., and Schubert, S. 2005. Osmotic stress and silicon act additively in enhancing pathogen resistance in barley against barley powdery mildew. J. Plant Nutr. Soil Sci. 168:269-274.

49. Wilkinson, S., Clephan, A. L., and Davies, W. J. 2001. Rapid low temperature-induced stomatal closure occurs in cold-tolerant Commelina communis leaves but not in cold-sensitive tobacco leaves, via a mechanism that involves apoplastic calcium but not abscisic acid. Plant Physiol. 126:1566-1578. 